\title{
Complications of Uterine Fibroid Embolization
}

\author{
Brian E. Schirf, M.D., ${ }^{1}$ Robert L. Vogelzang, M.D., ${ }^{1}$ \\ and Howard B. Chrisman, M.D., M.B.A. ${ }^{1}$
}

Objectives: Upon completion of this article, the reader should be able to discuss the avoidance, detection, and management of both procedural and delayed complications associated with uterine fibroid embolization.

Accreditation: Tufts University School of Medicine (TUSM) is accredited by the Accreditation Council for Continuing Medical Education to provide continuing medical education for physicians.

Credit: TUSM designates this educational activity for a maximum of 1 Category 1 credit toward the AMA Physicians Recognition Award. Each physician should claim only those credits that he/she actually spent in the activity.

Uterine fibroid embolization (UFE) is an increasingly popular minimally invasive treatment option for women with symptomatic fibroid disease. UFE therapy in qualified hands is an effective, well-tolerated procedure that offers relief of fibroid symptoms with a low risk of complications. The Society of Interventional Radiology Reporting Standards for Uterine Artery Embolization for the Treatment of Uterine Leiomyomata recommends that complications be categorized as related to: "angiography, pelvic infection, ischemia, post-embolization syndrome (prolonged admission, readmission, or escalation of care), ovarian failure, sexual dysfunction, fibroid tissue passage requiring intervention, non-gynecologic embolization (bowel, buttock, nerves, etc.), radiation injury, adverse drug reaction, pulmonary embolism, and other."1 Complications are further defined as minor or major events within each category $^{1}$ with major events resulting in an unplanned increased level of care or prolonged hospitalization. Overall, major complications typically occur in fewer
${ }^{1}$ Department of Radiology, Northwestern University, Chicago, Illinois.

Address for correspondence and reprint requests: Howard B. Chrisman, M.D., M.B.A., Vice Chairman, Clinical Operations, Department of Radiology, NUMS, 676 N. St. Claire Avenue, Suite 800, Chicago, IL 60611.
Complications in Interventional Radiology; Guest Editor, Jonathan Lorenz, M.D.

Semin Intervent Radiol 2006;23:143-149. Copyright (C) 2006 by Thieme Medical Publishers, Inc., 333 Seventh Avenue, New York, NY 10001, USA. Tel: +1(212) 584-4662.

DOI 10.1055/s-2006-941444. ISSN 0739-9529. 
than $4 \%$ of patients and minor complications occur in fewer than $23 \%$.

\section{ACUTE COMPLICATIONS}

In the acute postprocedural period, immediate complications may relate to vascular access, thromboembolic events, infection, and pain management. Most periprocedural complications are nonspecific to UFE and relate to vascular access and/or contrast agent use. These complications include arterial dissection, pseudoaneurysm, lower extremity emboli, puncture site hematoma, contrast allergy, contrast nephropathy, nerve injury, and infection.

An increased number of major access site complications were reported by Wagner et al associated with the use of suture-mediated closure devices (SMCDs) versus manual compression in the young female population undergoing uterine artery embolization (UAE). ${ }^{2}$ Sprouse et al noted an increased incidence of arterial infections with the use of percutaneous SMCDs. ${ }^{3}$ In a more recent prospective study of 342 consecutive UFE patients treated with SMCDs, no major complications (including infection) were reported with minor complications including small hematomas (1\%) and anteromedial thigh pain $(21 \%) .{ }^{4}$ The incidence of access site infection as reported by Sprouse et $\mathrm{al}^{3}$ may theoretically be less likely with the use of synthetic monofilaments versus braided vicryl sutures in SMCD equipment.

Inadequate acute pain management may result in the readmission of some patients for pain control. Postembolization syndrome is a well-described phenomenon consisting of pain, fever, nausea, leukocytosis, and occasionally malaise. ${ }^{5}$ Early identification of patients with infection or uterine necrosis during the immediate postembolization period is challenging. Triage of these patients may be facilitated by the use of contrast-enhanced magnetic resonance imaging (MRI) ${ }^{6}$ especially in patients with comparison pre-procedural MR imaging. ${ }^{7}$

\section{THROMBOEMBOLIC EVENTS}

Reported major complications include but are not limited to pulmonary embolus, uterine ischemia, necrosis, sepsis, and death. The period of immobility required after UFE is typically short but may place the patient at risk for deep venous thrombosis and pulmonary embolus, especially patients with venous compression by an enlarged fibroid uterus and an extended hospital stay resulting from complications. Such patients may benefit from daily subcutaneous heparin injections. Spies et al reported a pulmonary embolus as a single major complication in a series of 200 consecutive patients, ${ }^{8}$ and that patient was successfully treated with therapeutic anticoagulation.

\section{UTERINE INFECTION}

Endometritis and sepsis are rare complications associated with UFE. In a series of 414 patients who had UAE for fibroids, five intrauterine infections occurred requiring intravenous antibiotics or surgery $(1.2 \%) .{ }^{9}$ In the acute phase following UFE, fever and leukocytosis associated with postembolization syndrome may be indistinguishable from infection, and extended hospital stay with prophylactic intravenous antibiotics may be warranted. Delayed superinfection of necrotic, dominant fibroids has been described weeks to months after UFE in case reports, occasionally resulting in sepsis and requiring myomectomy or hysterectomy. In Fig. 1, marked heterogeneous contrast-enhancement obscures the uterine anatomy and is suggestive of infection. Early recognition of infection and appropriate antibiotic treatment may result in fewer patients undergoing precautionary hysterectomy. Reimaging with contrastenhanced MRI may show abscess formation or obstruction of the cervical os by necrotic material.

\section{UTERINE ISCHEMIA}

The goal of uterine fibroid embolization is to cause ischemia and necrosis of fibroids while preserving the uterus. In patients with worsening pain, close interval clinical and MRI follow-up is recommended to avoid the morbidity associated with sepsis and emergent hysterectomy.

In Fig. 2, initial post-contrast-enhanced images reveal only a thin edge of peripheral enhancement suggestive of global ischemia with the patient at risk of uterine necrosis. Subsequent images reveal increased perfusion of the myometrium, decrease in postprocedural edema, decrease in uterine size, and lack of enhancement in the targeted fibroids.

\section{UTERINE NECROSIS}

Uterine necrosis is a rare, major complication associated with UFE that if not aggressively treated can result in sepsis and death. Gabriel et al reported the utility of contrast-enhanced pelvic MRI in detecting uterine necrosis following UAE for fibroids. ${ }^{6}$

Fig. 3 shows a large submucosal fibroid and diffuse uterine necrosis. A sagittal T1-weighted gradient-echo image after administration of intravenous contrast material revealed marked hypoperfusion within the entire uterus, suggestive of uterine necrosis. An urgent hysterectomy was performed in this patient with the resulting correlative path specimen shown.

\section{DEATH}

At least three deaths are documented in the literature associated with UFE. One death occurred secondary to a 
A
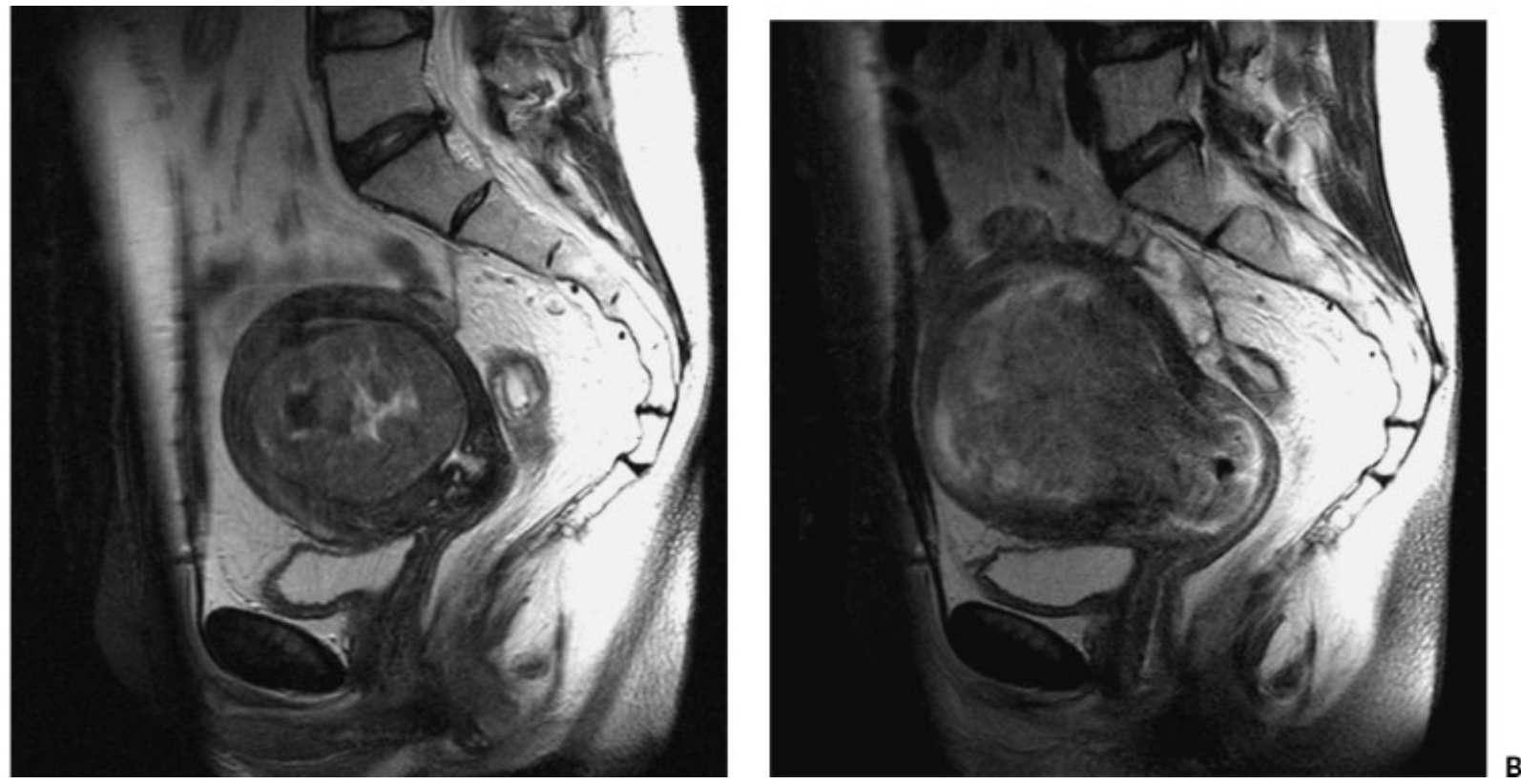

Figure 1 (A) Sagittal T2-weighted MRI shows a large submucosal fibroid; (B) sagittal T2 postcontrast image with marked heterogeneous enhancement obscuring the uterine anatomy.

large pulmonary embolus ${ }^{10}$ and two deaths resulted from uterine necrosis and sepsis with multiorgan system failure. $^{11,12}$

\section{SOFT TISSUE NECROSIS}

Nontarget embolization in one patient resulted in labial necrosis associated with ovarian failure and unilateral deep buttock pain. ${ }^{13}$ Dietz et al describe a case of fullthickness buttock necrosis from presumed misembolization requiring surgical debridement and secondary healing over the subsequent 14 weeks. $^{14}$ These major complications can be avoided by careful fluoroscopic monitoring of particle injections throughout the UFE procedure to detect the first signs of cessation of flow and prevent retrograde reflux into other branches of the anterior division of the internal iliac artery.

\section{EXPULSION OF FIBROID TISSUE}

Expulsion or discharge of small tissue fragments and necrotic material is a common minor complication of UFE, occurring in $2.5 \%$ of patients from a study of 400 consecutive UFE patients. ${ }^{15}$ Although sloughed fibroid tissue typically occurs after UFE in the first year, delayed reports of tissue passage have been reported as late as 50 months. ${ }^{16}$ Clinically, sloughing and expulsion of fibroids may be accompanied by abdominal pain and fever, particularly when secondary infection occurs. A major complication occurs when an infarcted fibroid persists partially exposed through the cervix - a nidus for infection that may lead to endometritis. Patients presenting with this problem are admitted to the hospital and provided immediate supportive care including intravenous fluids and antibiotics. In addition, the firstline therapeutic intervention is hysteroscopic removal, and in severe cases when this treatment fails, hysterectomy may be required. Fig. 4 shows a prolapsing necrotic rim enhancing fibroid.

Delayed onset of uterine hemorrhage requiring emergency hysterectomy was reported in a patient 1 month after UFE. ${ }^{17}$

\section{CHRONIC VAGINAL DISCHARGE}

Chronic vaginal discharge following UFE often results when a small communication forms between an infarcted, superficial fibroid and the endometrial cavity. In one study, $94 \%$ of patients' symptoms related to chronic vaginal discharge resolved spontaneously; hysteroscopic resection of the cavity was usually curative. ${ }^{18}$

\section{OVARIAN AND SEXUAL DYSFUNCTION}

Amenorrhea, both transient and permanent, has been reported as a complication associated with UFE. Permanent amenorrhea may result from nontarget embolization of the ovaries with resulting ovarian dysfunction, or secondary to endometrial atrophy. ${ }^{19}$ Chrisman et al reported a higher incidence of ovarian dysfunction and failure in women undergoing UFE over 45 years of age. $^{20}$ In recently published data from the FIBROID 

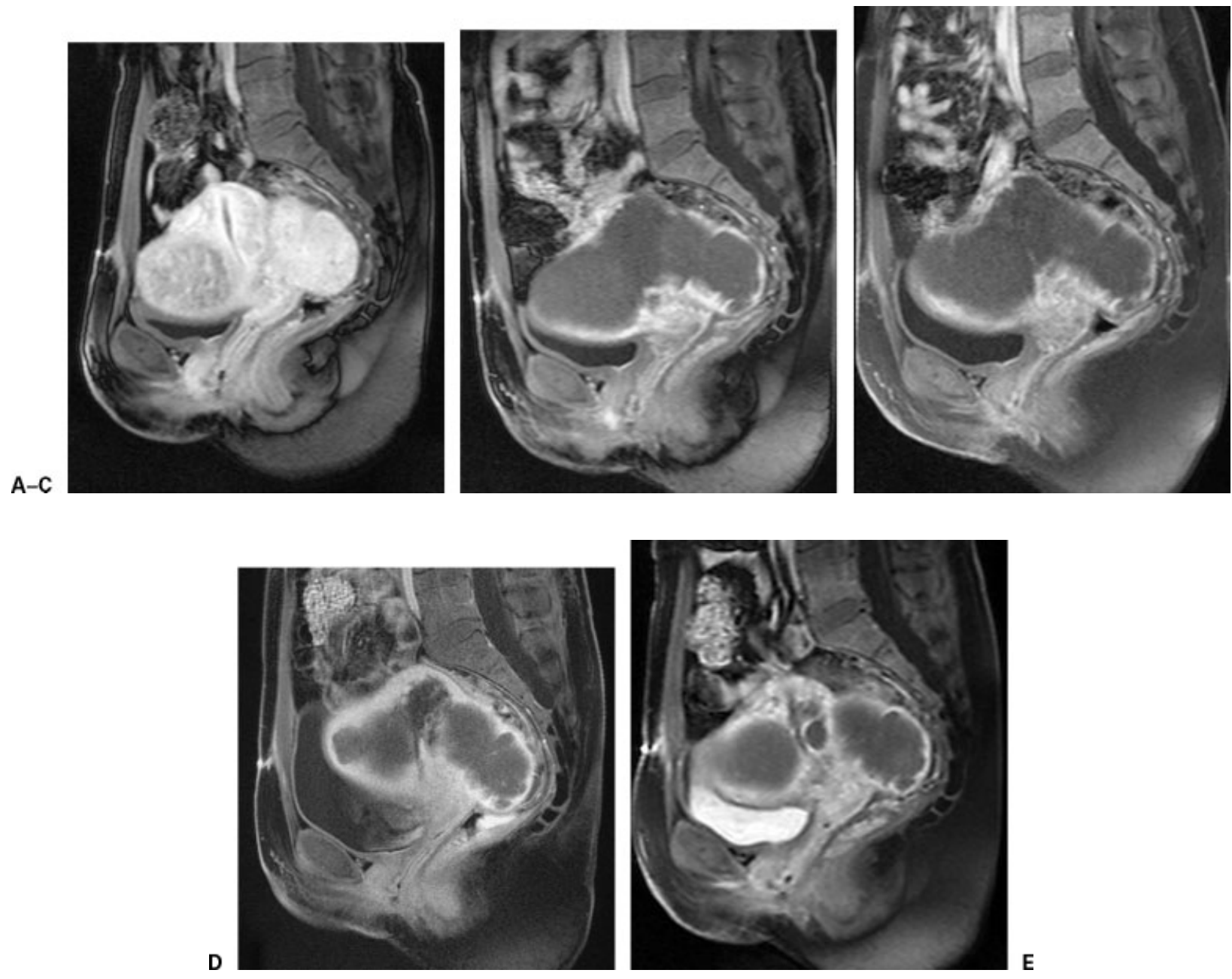

Figure 2 Severe uterine ischemia with recovery. (A) Preoperative sagittal T1 post-gadolinium-contrast administration. (B) Postoperative day 1: near complete loss of enhancement of the fibroids with a thin enhancing rim of endometrial uterine wall concerning for early necrosis (C). Postoperative day 3: follow-up shows slight internal increased uterine perfusion. (D) Postoperative day 7: continued interval improvement of uterine perfusion following the administration of gadolinium. (E) Postoperative day 21: slight decrease in overall size of the uterus with shrinking necrotic fibroids and interval increase in uterine enhancement.

Registry, $7.3 \%$ of patients undergoing UFE developed amenorrhea with $86 \%$ of these patients 45 years of age or older. ${ }^{21}$

A case of transient ovarian failure in a 49-year-old woman was reported by Amato and Roberts 3 months following UFE. ${ }^{22}$ In this patient who had developed amenorrhea, menses returned 7 months after embolization and her elevated serum follicle stimulating hormone level returned to normal. ${ }^{22}$

Loss of ability to achieve orgasm, both internal and clitoral, was reported by Lai et al in a 41-year-old woman 6 days after UFE. ${ }^{23}$ By her 6-month follow up, she reported an improvement in her pelvic pain, increase in energy and libido, and had regained the ability to achieve clitoral orgasm while her inability to achieve internal orgasm persisted. This finding may relate to nontarget embolization of cervicovaginal arterial branches.

\section{TREATMENT FAILURE}

Possible causes of failure of treatment include incomplete embolization, arterial spasm, recanalization of the arteries, prominent nonuterine artery collateral supply (often from the ovarian arteries ${ }^{24}$ ), and persistent effects of gonadotropin agonists such as leuprolide. Patients presenting with treatment failure often have imaging findings demonstrating regrowth of fibroids or residual viable fibroid. Persistent pain after UFE is sometimes seen in patients with sloughing fibroid material, and careful follow up is essential to detect signs of superimposed endometritis. In patients with prior pelvic surgery, tubo-ovarian pathology, and/or fundal fibroids, Pelage et al recommended flush aortography with possible superselective catheterization to evaluate for significant contributory flow from the ovarian arteries during UFE. ${ }^{25}$ 
A
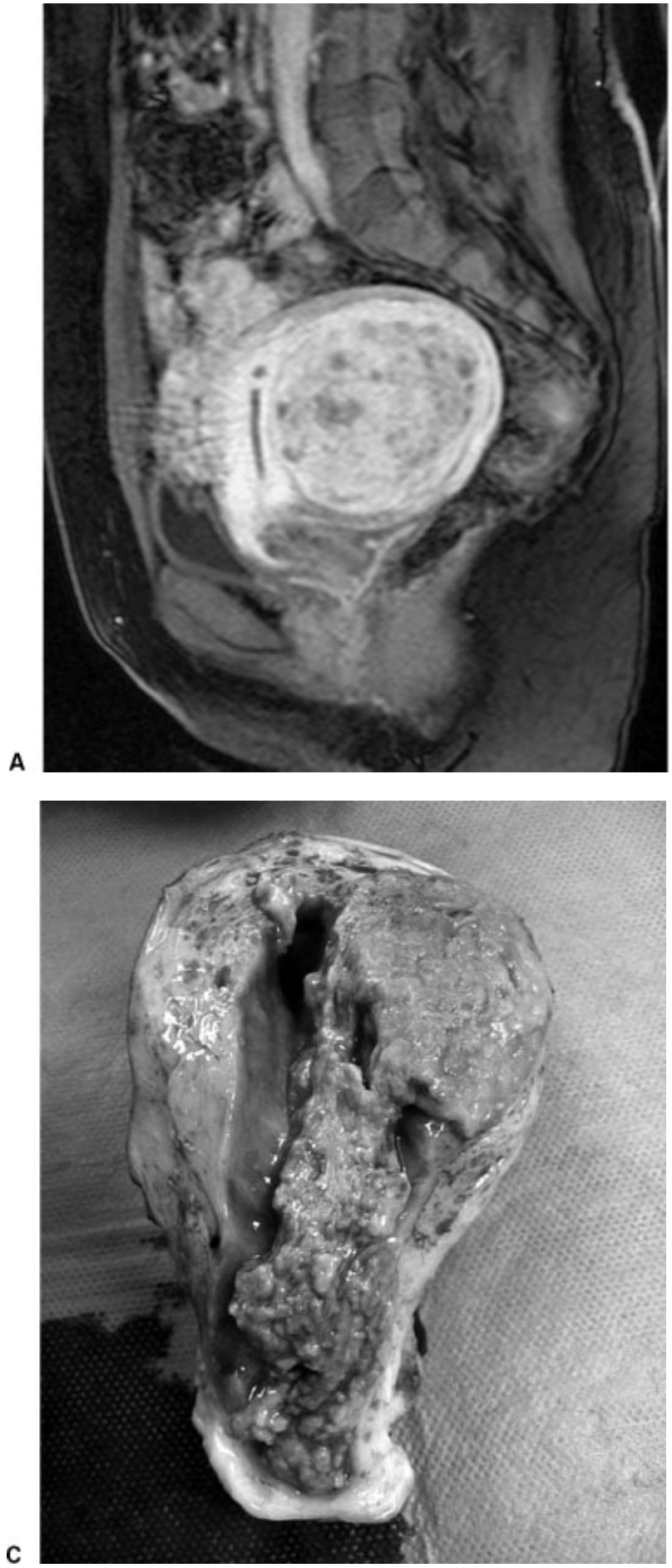

Recent 5-year follow-up data from a prospective study of 200 consecutive patients who had undergone UFE by Spies et al found that although a majority of patients experienced persistent symptom relief, there was a $25 \%$ chance of failure with loss of symptom control. ${ }^{26}$ Failure was defined as "subsequent hysterectomy, definitive myomectomy, repeat embolization, or failure of symptom improvement at the patient's final follow-up." 26

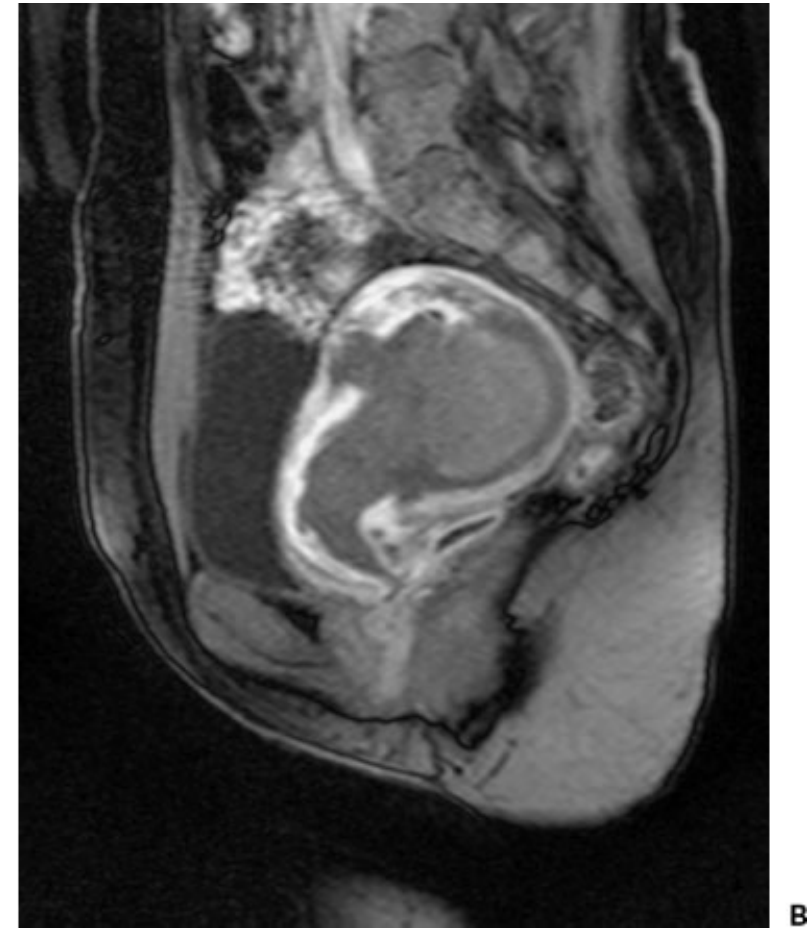

Figure 3 (A-C) Uterine necrosis. (C) Gross pathological specimen following urgent hysterectomy.

\section{COMPLICATIONS OF SUBSEQUENT PREGNANCY}

Theoretically, one would expect that the findings such as persistent necrotic fibroids observed on imaging studies after UFE would lead to complications of subsequent pregnancies, and this procedure is still not recommended for patients intending to become pregnant. Though only limited studies have evaluated complications associated with pregnancy after UFE, one of the largest studies of 
A
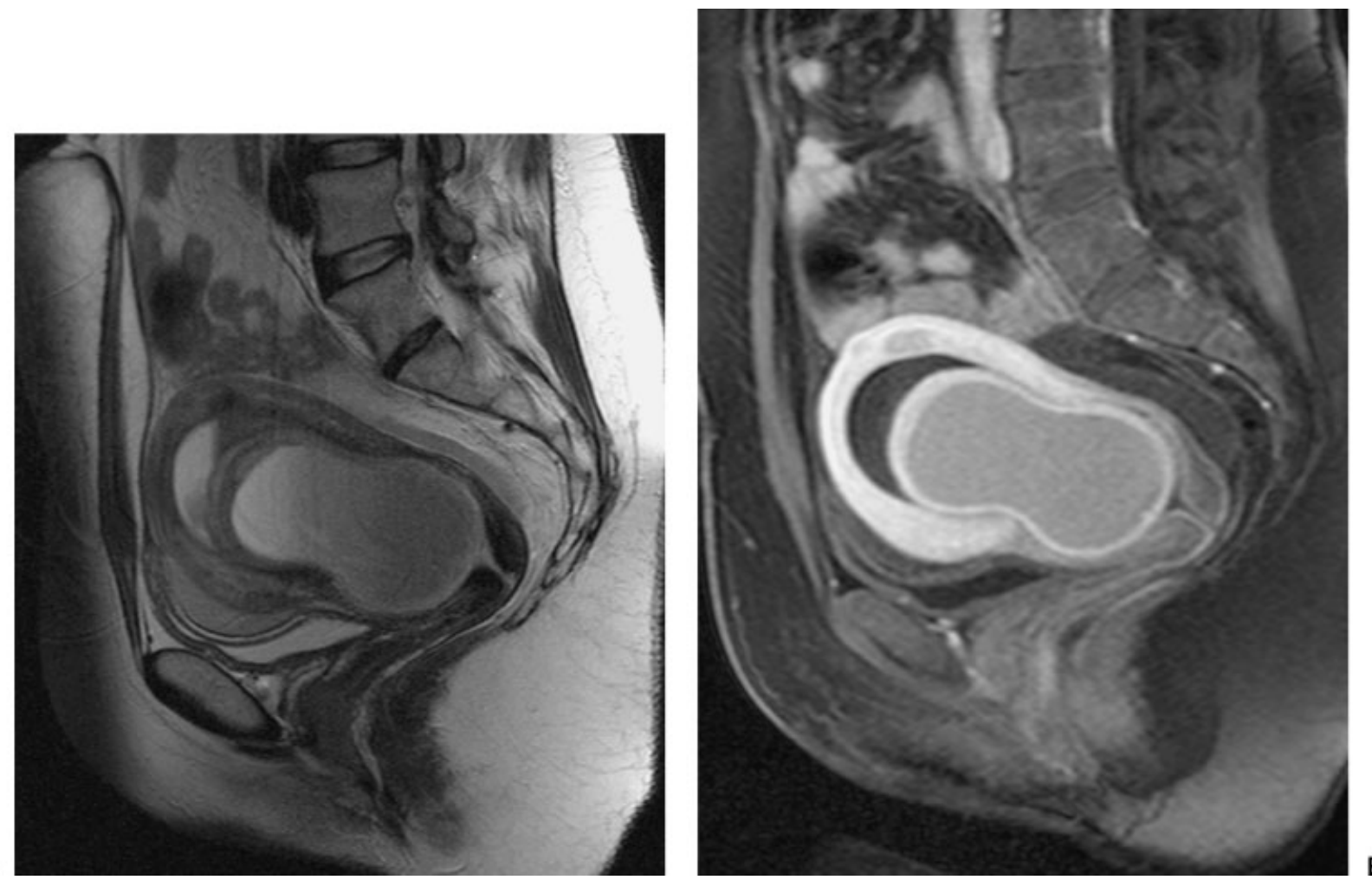

Figure 4 Prolapsing fibroid seen on (A) pre- and (B) postcontrast sagittal T2 images.

26 completed pregnancies by Carpenter and Walker showed only an increased rate of cesarean section in this population. When the advanced age and demographics of these patients was considered, no other obstetric risk associated with these pregnancies was observed. ${ }^{27}$

\section{CONCLUSION}

UFE is a safe alternative to surgical myomectomy, resulting in shorter hospital stay, fewer and less severe adverse events, and similar rates of technical and clinical success. Awareness of the known complications of UFE may allow more rapid diagnosis and effective therapeutic responses to complications when they occur.

\section{ACKNOWLEDGMENTS}

The authors would like to thank Joshua Tepper, M.D. and Shashin Doshi, M.D. for their assistance with the figures.

\section{REFERENCES}

1. Goodwin SC, Bonilla SC, Sacks D, et al. Reporting standards for uterine artery embolization for the treatment of uterine leiomyomata. J Vasc Interv Radiol 2003;14:S467-S476
2. Wagner SC, Gonsalves CF, Eschelman DJ, Sullivan KL, Bonn J. Complications of a percutaneous suture-mediated closure device versus manual compression for arteriotomy closure: a case-controlled study. J Vasc Interv Radiol 2003;14: 735-741

3. Sprouse LR, Botta DM, Hamilton IN. The management of peripheral vascular complications associated with the use of percutaneous suture-mediated closure devices. J Vasc Surg 2001;33:688-693

4. Chrisman HB, Liu DM, Bui JT, et al. The safety and efficacy of a percutaneous closure device in patients undergoing uterine artery embolization. J Vasc Interv Radiol 2005;16: 347-351

5. Hemingway A. Complications of embolotherapy. In: Kadir S, ed. Current Practice of Interventional Radiology. Philadelphia: Decker; 1991:104-109

6. Gabriel H, Pinto CM, Kumar M, et al. MRI detection of uterine necrosis after uterine artery embolization for fibroids. AJR Am J Roentgenol 2004;183:733-736

7. Omary RA, Vasireddy S, Chrisman HB, et al. The effect of pelvic MR imaging on the diagnosis and treatment of women with presumed symptomatic uterine fibroids. J Vasc Interv Radiol 2002;13:1149-1153

8. Spies JB, Ascher SA, Roth AR, Kim J, Levy EB, GomezJorge J. Uterine artery embolization for leiomyomata. Obstet Gynecol 2001;98:29-34

9. Rajan DK, Beecroft JR, Clark TWI, et al. Risk of intrauterine infectious complications after uterine artery embolization. J Vasc Interv Radiol 2004;15:1415-1421

10. Lanocita R, et al. A fatal complication of percutaneous transcatheter embolization for treatment of uterine fibroids. 
Paper presented at: Society of Minimally Invasive Therapy/ Center for Innovative Minimally Invasive Therapy, 11th International Conference; September 16-18, 1999; Boston, MA

11. de Blok S, de Vries C, Prinssen HM, Blaauwgeers HLG, Jorna-Meijer LB. Fatal sepsis after uterine artery embolization with microspheres. J Vasc Interv Radiol 2003;14:779784

12. Vashisht A, Studd J, Carey A, Burn P. Fatal septicaemia after fibroid embolisation. Lancet 1999;354:307-308

13. Yeagley TJ, Goldberg J, Klein TA, Bonn J. Labial necrosis after uterine artery embolization for leiomyomata. Obstet Gynecol 2002;100:881-882

14. Dietz DM, Stahlfeld KR, Bansal SK, Christopherson WA. Buttock necrosis after uterine artery embolization. Obstet Gynecol 2004;104:1159-1161

15. Spies JB, Spector A, Roth AR, Baker CM, Mauro L, Murphy-Skrynarz K. Complications after uterine artery embolization for leiomyomas. Obstet Gynecol 2002;100: 873-880

16. Marret H, Keris YLB, Acker O, Cottier JP, Herbreteau D. Late leiomyoma expulsion after uterine artery embolization. J Vasc Interv Radiol 2004;15:1483-1485

17. Kerlan RK Jr, Coffey JO, Milkman MS, et al. Massive vaginal hemorrhage after uterine fibroid embolization. J Vasc Interv Radiol 2003;14:1465-1467

18. Walker WJ, Carpenter TT, Kent ASH. Persistent vaginal discharge after uterine artery embolization for fibroid tumors: cause of the condition, magnetic resonance imaging appearance, and surgical treatment. Am J Obstet Gynecol 2004;190: $1230-1233$
19. Tropeano G, Litwicka K, Di Stasi C, Romano D, Mancuso S. Permanent amenorrhea associated with endometrial atrophy after uterine artery embolization for symptomatic uterine fibroids. Fertil Steril 2003;79:132-135

20. Chrisman HB, Saker MB, Ryu RK, et al. The impact of uterine fibroid embolization on resumption of menses and ovarian function. J Vasc Interv Radiol 2000;11:699-703

21. Spies JB, Myers ER, Worthington-Kirsch R, et al. The FIBROID registry: symptom and quality-of-life status 1 year after therapy. Obstet Gynecol 2005;106:1309-1318

22. Amato P, Roberts AC. Transient ovarian failure: a complication of uterine artery embolization. Fertil Steril 2001;75: 438-439

23. Lai AC, Goodwin SC, Bonilla SM, et al. Sexual dysfunction after uterine artery embolization. J Vasc Interv Radiol 2000; 11:755-758

24. Matson M, Nicholson A, Belli A-M. Anastomoses of the ovarian and uterine arteries: a potential pitfall and cause of failure of uterine embolization. Cardiovasc Intervent Radiol 2000;23:393-396

25. Pelage JPWW, Le Dref O, Rymer R. Ovarian artery: angiographic appearance, embolizaton and relevance to uterine fibroid embolization. Cardiovasc Intervent Radiol 2003;26: 227-233

26. Spies JB, Bruno J, Czeyda-Pommersheim F, Magee ST, Ascher SA, Jha RC. Long-term outcome of uterine artery embolization of leiomyomata. Obstet Gynecol 2005;106:933939

27. Carpenter TT, Walker WJ. Pregnancy following uterine artery embolisation for symptomatic fibroids: a series of 26 completed pregnancies. BJOG 2005;112:321-325 